\title{
Single-Stage Grid Tied Converter to Improve Solar PV Array Performance and Power Quality in Microgeneration-Consumers Units
}

\author{
Paulo Robson Melo Costa \\ Postgraduate Program in Electrical \\ and Computer Engineering \\ Federal University of Ceara \\ Sobral, Brazil \\ robsoncee@gmail.com \\ Marcus Rogério de Castro \\ Postgraduate Program in Electrical \\ and Computer Engineering \\ Federal University of Ceara \\ Sobral, Brazil \\ marcusdecastro@yahoo.com.br
}

\author{
Larissa Souza Pereira \\ Postgraduate Program in Electrical \\ and Computer Engineering \\ Federal University of Ceara \\ Sobral, Brazil \\ laris.sal@hotmail.com \\ Isaac Rocha Machado \\ Postgraduate Program in Electrical \\ and Computer Engineering \\ Federal University of Ceara \\ Sobral, Brazil \\ isaacmachado@gmail.com
}

\author{
Yury Pontes \\ Postgraduate Program in Electrical \\ and Computer Engineering \\ Federal University of Ceara \\ Sobral, Brazil \\ yuryeletrica@hotmail.com
}

\begin{abstract}
The main purpose of this paper is to present the combination of the renewable energy generation and power conditioners benefits in microgeneration systems. This is done through a Voltage Source Converter (VSC) used to maximize the efficiency of a photovoltaic (PV) solar array and, at the same time, filtering the harmonic currents of non-linear loads present in consumer units equipped with distributed microgeneration. In this way, the VSC is used to implement the Maximum Power Point Tracking (MPPT) algorithm and act as a Shunt Active Filter (SAF), forming a so-called PV-SAF system. The main strategy of the proposed system is to maximize the operating range of the DC bus voltage to perform current harmonic filtering and enable maximum power tracking satisfactorily using the p-v curve over a wide operating range. The proposed PV-SAF system uses a three-phase single-stage topology and can track the maximum power point (MPP) even in partial shading condition (PSC). The PSIM software is used to perform the simulations of the proposed PV-SAF system, the simulation results validate the control strategy that is capable of performing the reactive power compensation, current harmonics filtering and active power management produced by a PV array.
\end{abstract}

Keywords-Solar photovoltaic (PV), Maximum Power Point Tracking (MPPT), Shunt Active Filter (SAF), power quality.

\section{INTRODUCTION}

PV systems convert solar radiation into electricity without producing noises, residues or polluting gases emission. Allied to these characteristics, the considerable decrease in PV modules prices in recent years has made the use of this technology more attractive. Currently the PV solar system is one of the most widely generation technologies used in residential and commercial installations. With low environment impact, its installation is simple and usually close to non-linear loads. Global PV generation capacity increased approximately one third in 2017, reaching 402 GW [1]. Due to intermittent generation characteristic, the PV generation can be used in conjunction with a battery bank (Off-Grid) or grid connected via an VSC (On-Grid) so-called Grid-Tied Converter [2]. In On-grid PV systems, the electrical grid acts as a power storage and has been more used due to lower installation costs.

The power-voltage ( $\mathrm{p}-\mathrm{v})$ curve of an PV array depends on the operating conditions (irradiance and temperature) of each PV module [3]. When the irradiance is uniform in all modules (Uniform Shading Condition - USC), the p-v curve has only one Maximum Power Peak (MPP). When the modules are submitted to different irradiance levels (Partial Shading Condition - PSC), the p-v curve of the PV array may have several power peaks, being only one the Global Maximum Power Peak (GMPP) and the remaining being Local Maximum Power Peaks (LMPP) [4]. Fig. 6 presents P-V curves when the PV array is in USC and in PSC, cases 1 and 2 , respectively.

The MPPT algorithm consists in varying the PV array voltage until it reaches a maximum generated power value. Several MPPT techniques have been discussed in the literature [5], however, in some algorithms, the tracking may be confined to some LMPP. The GMPP tracking (GMPPT) techniques presented in [3] can solve this impasse.

In PV-SAF systems with single-stage topology, only conventional MPPT techniques have been used. In [6] the performance of the Incremental Conductance (IC) algorithm is evaluated. In [7] and [8] the algorithm Perturb \& Observe (P\&O) was proposed and evaluated. In these works, the VSC $\mathrm{DC}$ bus voltage is designed to match the maximum power voltage of the PV array. In this way, the PV array voltage is not explored in a wide range to track possible peaks in PSC cases.

On the other hand, in installations equipped with distributed generation, power quality problems are always common due to non-linear loads presence. Equipment such as power supplies, LED's, fluorescent lights, electronic devices, etc., change the sinusoidal nature of the electrical current. The presence of harmonic and reactive components in the electrical current causes overloading of the conductors and can affect sensitive loads, such as hospital and industrial 
equipment. The Shunt Active Filter (SAF) can eliminate for these undesirable harmonic components so that only the fundamental current component is supplied by the grid [9].

In addition to reactive and harmonic power compensation, the SAF can also be used for active power grid injection if there is any energy source connected to DC bus, such as fuel cell or solar PV array. If the PV array is used, the system is socalled PV-SAF system. The single-stage topology designation derives from connecting the PV Array directly to the DC bus, eliminating the use of an intermediate DC/DC converter, increasing system efficiency and decreasing the number of circuit components. The disadvantage of this topology is the need for a large number of PV modules connected in a string to achieve the DC bus voltage compatible with the AC grid voltage.

Several SAF control strategies were proposed, such as the control based on the PQ theory [10-12], lattice wave digital filter (LWDF) based control approach [13], adaptive controls schemes [6], synchronous reference frame theory (SRF) [7] and character of triangle function (CTF) control technique [8].

This work presents the design and analysis of a PV-SAF system with single-stage topology optimized for the GMMPT algorithm execution. The system is evaluated in Partial Shading Condition and non-linear load. The SAF control strategy is based on the PQ or instantaneous powers theory and the GMPPT technique is based on the estimation of the possible power peaks location in $\mathrm{p}-\mathrm{v}$ curve. The main advantages of the proposed system are:

1) Development of a topology that combines renewable energy management with power quality improvement for microgenerating-consuming units;

2) Power factor improvement during day and night;

3) Improvement in the harmonics filtering performance due to the Moving Average Filter (MAF) used to separate the instantaneous powers components (average and oscillating components);

4) Simplified topology (single-stage), eliminating the use of an intermediate DC/DC converter, decreasing losses and complexity;

5) PV array efficiency improvement in PSC due to the fast GMPPT algorithm proposed;

6) Operating voltage range (tracking voltage range) increasing due to the use of the Space Vector Modulation (SVPWM) technique. For a given rated grid voltage, the SVPWM technique allows the use of a lower DC-bus voltage without compromising vectorial current control.

The performance of the proposed system is analyzed in a permanent and transient periods through simulations implemented in the PSIM software.

\section{System STRUCTURE AND DESIGN}

Fig. 1 shows the power diagram of the proposed PV-SAF system. The main system blocks are the PV array, the voltage source converter (VSC), the ripple filter, the grid and the nonlinear load.

The PV Array generated power is injected in the DC bus of the VSC. The DC bus voltage is variable and controlled in a certain voltage range to perform the maximum power point tracking of the PV array. This point depends on the operating

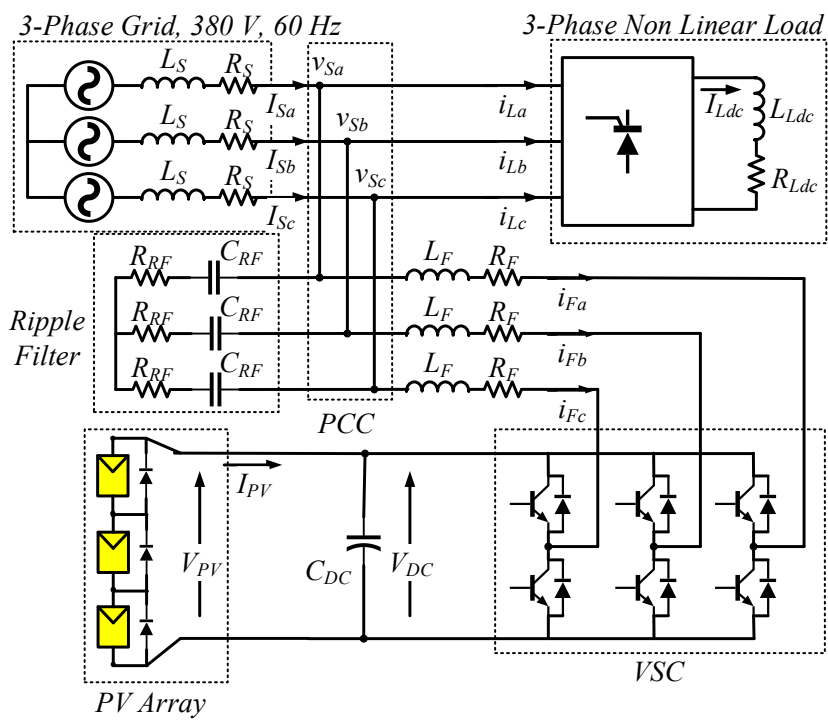

Fig. 1. System configuration PV-SAF.

conditions of the PV array modules, irradiance and temperature. The VSC acts as a DC-AC converter and injects a current in the grid composed of the reactive and harmonic compensation components of the load and a component due the power generated by the PV Array, which is delivered to the DC bus. The Ripple filter is a first-order high-pass filter and is connected to the Point Common Coupling (PCC), its function is to eliminate the voltage harmonics produced by the VSC in the switching frequency.

The other essential system elements are DC bus capacitance $\left(C_{D C}\right)$, which attenuates voltage fluctuation on the DC bus, and coupling inductances $\left(L_{F}\right)$, which limit the derivative of the VSC output current.

\section{A. Design of $P V-S A F$}

The design of a PV-SAF system consists of the proper sizing of the PV array, the shunt active filter and its components (DC bus voltage, DC bus capacitor, coupling inductor, etc.) and the Ripple filter depending on the power grid and load characteristics.

\section{1) Supply (Grid) Characteristics}

The three-phase three-wire symmetrical supply with line voltage $V_{S}=380 \mathrm{~V}$ and frequency $f=60 \mathrm{~Hz}$, with series resistance $R_{S}=0.04 \Omega$ and series inductance $L_{S}=0.1 \mathrm{mH}$ is considered. The IEEE-519 standard guides the maximum limits of harmonic injection in the electricity grid by the consumer. For electrical systems with rated voltage between $120 \mathrm{~V}$ and $69 \mathrm{kV}$, the standard recommends the maximum total harmonic distortion (THD) limit of 5\% at the common connection point (PCC) [14].

2) Load Characteristics

A three-wire three-phase thyristor-controlled rectifier with firing angle $\alpha=\pi / 6 \mathrm{rad}\left(30^{\circ}\right)$ and inductive load ( $R_{L d c}=10 \Omega$ and $L_{L d c}=100 \mathrm{mH}$ ) is used as the non-linear load. The rectified output current is $I_{L d c}=40.2 \mathrm{~A}$.

The rms current at the rectifier input $\left(I_{L}\right)$, the same in all phases, is

$$
I_{L}=\sqrt{(\pi / 2+\alpha) / \pi} \cdot I_{L d c}=32.8 \mathrm{~A} .
$$

The apparent power in load $\left(\mathrm{S}_{\mathrm{L}}\right)$ is given by $(2)$.

$$
S_{L}=\sqrt{3} \cdot V_{S} \cdot I_{L}=21.6 \mathrm{kVA}
$$


Equation (3) shows the rms fundamental component (1st harmonic) of the rectifier input current $\left(I_{L 1}\right)$.

$$
I_{L 1}=2 \sqrt{2} \cdot I_{L d c} \cdot \sin (\pi / 4+\alpha / 2) / \pi=31.3 \mathrm{~A}
$$

The first harmonic displacement angle of rectifier input current with reference to voltage phase $(\theta)$ is the same of thyristor firing angle $(\alpha), \theta=30^{\circ}$.

The load active power in the fundamental frequency $\left(P_{L}\right)$ is given.

$$
P_{L}=\sqrt{3} \cdot V_{S} \cdot I_{L 1} \cdot \cos (\theta)=17.8 \mathrm{~kW}
$$

Equation (5) shows the total load reactive power $\left(Q_{L}\right)$ in the fundamental frequency.

$$
Q_{L}=\sqrt{3} \cdot V_{S} \cdot I_{L 1} \cdot \sin (\theta)=10.3 \mathrm{kVAr}
$$

The harmonic content of rectifier input current $\left(\mathrm{I}_{\mathrm{Lh}}\right)$ is given by:

$$
I_{L h}=\sqrt{I_{L}^{2}-I_{L 1}^{2}}=9.7 \mathrm{~A} .
$$

So, the total harmonic power on the load, given by $H_{L}$, is:

$$
H_{L}=\sqrt{3} \cdot V_{S} \cdot I_{L h}=6.4 \mathrm{kVA} \text {. }
$$

For $n=1,3,5, \ldots$, the $\mathrm{n}^{\text {th }}$ harmonic of rectifier input current can be given by (8).

$$
i_{L n}=\frac{4 I_{L d c}}{n \pi} \sin \left(\frac{n(\pi / 2+\alpha)}{2}\right) \cos \left(2 \pi n f t+\delta_{n}\right)
$$

Calculating the time-derivative of equation (8), the maximum slope for the $\mathrm{n}^{\text {th }}$ harmonic is obtained.

$$
\left(\frac{d i_{L n}}{d t}\right)_{\max }=\frac{8 f I_{L d c}}{n} \sin \left(\frac{n(\pi / 2+\alpha)}{2}\right)
$$

Thus, given that $i_{L}=\sum i_{L n}$, it follows:

$$
\left(\frac{d i_{L}}{d t}\right)_{\max }=\sum_{n=1}^{\infty}\left(\frac{d i_{L n}}{d t}\right)_{\max } .
$$

The result of (10), up to $50^{\text {th }}$ harmonic component is calculated, in according to IEEE-519, and the maximum derivative $i_{L}$ is:

$$
\left(\frac{d i_{L}}{d t}\right)_{\max }=284.1 \mathrm{kA} / \mathrm{s}
$$

\section{3) SAF Design}

The shunt active filter (SAF) design comprises the VSC project and passive components sizing.

Based on design criteria taking account the load and grid characteristics, the DC bus voltage level $\left(V_{D C}\right)$, DC bus capacitance $\left(C_{D C}\right)$, coupling inductance $\left(L_{F}\right)$, switching frequency $\left(f_{S}\right)$ and ripple filter $\left(R_{R F}\right.$ and $\left.C_{R F}\right)$ are determinates.

The design parameters used for the SAF were: $2 \%$ of maximum ripple in the DC bus voltage $\left(\Delta V_{D C}\right)$; maximum output current ripple $\Delta I_{F}=6 \%$. The switching frequency is $f_{s}=100 \mathrm{kHz}$.

The SAF is used to compensate all reactive and harmonic content of the current load. In addition, the energy generated by the PV Array must be injected in the power grid. Taking account the result of the maximum power generated by the PV Array at (19) and adding a 25\% margin for transients, a nominal power of the SAF is given by (12).

$$
S_{A P F}=1.25 \sqrt{P_{P V}^{2}+Q_{L}^{2}+H_{L}^{2}}=17.4 \mathrm{kVA}
$$

So, $18 \mathrm{kVA}$ is considered.

The DC bus voltage operating range must be chosen to ensure the compensation of the maximum derivative load current in (11). At the same time, it must also be limited to keep the current ripple at acceptable levels.
The lower limit of the $V_{D C}$ operating range $\left(V_{D C m i n}\right)$ depends of the rated power grid voltage and the kind of modulation applied to control the VSC power switches.

The Space Vector modulation technique was chosen due to the DC bus more efficient use and the lower harmonic voltage distortion compared to the sinusoidal PWM (SPWM) or Hysteresis technique [15].

Considering the maximum modulation index in the submodulation region operation, $\mathrm{m}=0.907$, the $V_{D C \min }$ can be chose by (13) [16]:

$$
V_{D C \min }=\sqrt{2} V_{S} / m=590 \mathrm{~V}
$$

After that, the coupled inductance is computed to limit the high frequencies components of current and at the same time, allows the harmonic compensating. Therefore, is necessary ensuring that [17]:

$$
\begin{gathered}
L_{F} \leq\left(V_{D C \min }-V_{S} / \sqrt{3}\right) /\left(d i_{L} / d t\right)_{\max } \\
=0.99 \mathrm{mH}
\end{gathered}
$$

The maximum DC bus voltage is designed to maintain the ripple of the filter output current within the acceptable threshold $\left(\Delta I_{F}\right)$ to the designed coupling inductance value. Considering the result obtained in (12), the SAF output current peak value is: $I_{F P}=\sqrt{2 / 3} S_{A P F} / V_{S}$. The upper limit of the $V_{D C}$ operating range $\left(V_{D C \max }\right)$ is defined in (15) [17].

$$
V_{D C \max }=2 L_{F} I_{F p} \Delta I_{F} f_{S}+\sqrt{2 / 3} V_{S}=774.4 \mathrm{~V}
$$

The DC bus capacitance sizing is based on the DC bus voltage ripple resulting from load unbalance ( $2^{\text {th }}$ harmonic) [9].

$$
C_{D C}=\frac{S_{A P F}}{4 \pi \Delta I_{F} f \Delta V_{D C} V_{D C \max }^{2}}=1991 \mu F .
$$

Was considered $C_{D C}=2000 \mu \mathrm{F}$.

For the sizing of the Ripple Filter, the filter time constant must be much shorter than the power grid fundamental frequency $(f), R_{R F} C_{R F}<1 / f$. Considering $R_{R F} C_{R F}=2 T_{S}$, where $R_{R F}$ and $C_{R F}$ are the resistance and the capacitance of the Ripple Filter, respectively, and $T_{S}$ are the switching period of the VSC. Since the switching frequency is equal to $100 \mathrm{kHz}$, the selected ripple filter parameters are $R_{R F}=5 \Omega$ and $C_{R F}=4 \mu \mathrm{F}$. The filter impedance at the switching frequency is $5.0 \Omega$ and at the fundamental frequency is $663.2 \Omega$, which is sufficiently large and thus the ripple filter drains a negligible current at the fundamental frequency [9].

After the design of the SAF, is presented the proper sizing of the PV array.

\section{B. PV Array Design}

In the PV array design, the number of PV modules and how they are connected must be chosen. In the single-stage topology, the PV array is directly connected to the DC bus of the VSC. So, without the step-up (boost) stage, the modules must be connected in series to reach the required DC bus voltage. The maximum power voltage of the modules in series $\left(V_{M P P, a}\right)$, should be within the operating voltage range of the DC bus.

The PV module chosen is Kyocera's KD210TM. Being $G$ the irradiance and $T$ the temperature over the PV modules, the module parameters under standard test conditions (STC, $G=1000 \mathrm{~W} / \mathrm{m}^{2}$ and $T=25^{\circ} \mathrm{C}$ ) are: the generated power ( $\left.\mathrm{P}_{\mathrm{mSTC}}\right)$ is $210 \mathrm{~W}$, the open circuit voltage $\left(\mathrm{V}_{\mathrm{OC}, \mathrm{mSTC}}\right)$ is $33.2 \mathrm{~V}$ and the maximum power voltage $\left(\mathrm{V}_{\mathrm{MPP}, \mathrm{mSTC}}\right)$ is $26.6 \mathrm{~V}$. 
The PV curves in various operating conditions provided by the manufacturer datasheet were used to obtain the physical model parameters of the simulated PV module in the PSIM software. The physical model of the PSIM PV module is used to verify the module behavior in two extreme conditions: high irradiance with high temperature (operating condition 1) or low irradiance with low temperature (operating condition 2). It is considered the installation on the Brazil Northeast region.

The PV module parameters under operating condition 1 $\left(G=1400 \mathrm{~W} / \mathrm{m}^{2}\right.$ and $\left.T=75^{\circ} \mathrm{C}\right)$ are given: power generated $P_{m l}=227.3 \mathrm{~W}$, open circuit voltage $V_{O C, m I}=27.4 \mathrm{~V}$ and voltage in maximum power operating $V_{M P P, m l}=21.1 \mathrm{~V}$.

In the operating condition $2,\left(G=400 \mathrm{~W} / \mathrm{m}^{2}\right.$ and $\left.T=30^{\circ} \mathrm{C}\right)$, the module parameters are: power generated $P_{m 2}=81.3 \mathrm{~W}$, open circuit voltage $V_{O C, m 2}=31.5 \mathrm{~V}$ and voltage in maximum power operating $V_{M P P, m 2}=25.8 \mathrm{~V}$.

The number of modules connected in series $(\mathrm{N})$ is chosen in such way that the voltage in maximum power operating condition of the PV array must be lower than the maximum DC bus voltage allowed. This voltage will be maximum when the PV modules are operating in condition 2.

$$
N \leq V_{D C \max } / V_{M P P, m 2}=30.0
$$

$\mathrm{N}=30$ modules connected in series are supported.

Considering all PV modules under the same operating conditions (USC), the lowest value of $V_{M P P, a}$ will occur when the array are in operating condition 1 .

$$
\left(V_{M P P, a}\right)_{\min }=N \cdot V_{M P P, m 1}=633.0 \mathrm{~V}
$$

Since the minimum allowable voltage for the DC bus of the VSC is still less than the lower voltage of the PV array in USC (Uniform Shading Condition), a GMPPT algorithm can be used to locate the overall peak of the p-v curve in PSC (Partial Shading condition). The difference between the minimum voltage of the DC bus, $V_{D C m i n}$, and the minimum MPP voltage in USC, $\left(V_{M P P, a}\right)_{\min }$, makes it possible, together with a GMPPT technique, that the total generation of the arrangement is not impaired if partial or total shading occurs in up to 6 modules ( $20 \%$ of the PV array).

A shaded module would limit the current of all modules in series. However, the GMPPT technique allows finding the new global operating point at full power, thereby reducing the operating voltage of the array. A PV array voltage reduction causes the modules with low irradiance to be short circuited by their respective bypass diodes, so that the current of the assembly is no longer limited by the shaded modules.

Operation at the maximum power of the PV array occurs when all modules are in operational condition 1.

$$
P_{P V}=N \cdot P_{m 1}=6.82 \mathrm{~kW}
$$

Since the power structure was presented and sized, the control techniques of the system are now being studied.

\section{CONTROL TECHNIQUE OF PV-SAF}

The PV-SAF System control strategy is divided into two main functions. The first concerns the GMPP tracking of the PV Array to extract the maximum power within the established DC bus voltage range. The second is the SAF reference currents calculations using the instantaneous power theory.

\section{1) GMPPT Algorithm}

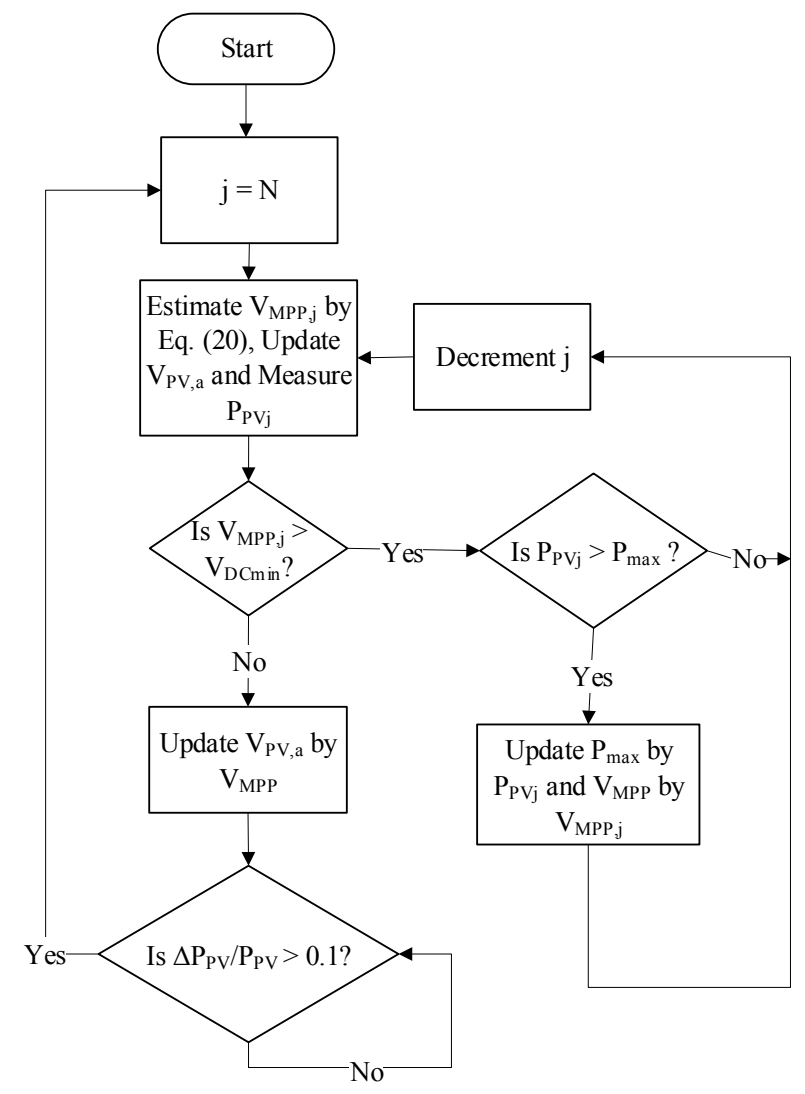

Fig. 2. Proposed GMPPT algorithm.

Fig. 2 shows the flowchart of the proposed GMPPT algorithm. According to [18], (20) can find the location of the possible power peaks in the $\mathrm{p}-\mathrm{v}$ curve. This strategy is a correction of the Fractional Open-Circuit Voltage technique, which approximates the maximum power peak voltage by $V_{M P P}=k_{1} V_{O C}$, where $V_{O C}$ is the open circuit voltage and $k_{1}$ is a proportionality constant and has its value between 0.71 and 0.80 [5]. This relation is valid for one module, however, when the number of modules is large the error is accumulated and makes it unusable [18].

$$
V_{M P P, j}=\left[a(j-1)+k_{1}\right] V_{O C, m}
$$

In (20), $a$ is a constant with a value ranging from 0.8 to 0.97 and $j$ is the number of the possible peaks that varies from 1 to N. Based on the analysis of the PV Array subjected to various operating conditions, the following constants $k l=0.75$ and $a=0.83$ were used in the proposed system.

With this, it is possible to track the LMPPs more quickly by jumping directly to the locations where these possible peaks would be located within the allowable DC bus voltage range. The measures of power at these points are compared to verify which is the GMPP. Periodically the generated power change is verified, if this variation is greater than $10 \%$ it is assumed that the operating conditions of the PV Array have changed and the tracking is redone to find a possible new GMPP.

\section{2) Shunt SAF Control}

Fig. 3 shows the control scheme of the SAF using PQ theory. Three-phase load currents and the PCC voltages are measured and used to calculate the real $(p)$ and imaginary $(q)$ powers.

Clark's Transformation in (21) transforms these threephase PCC voltages into two-phase $\alpha-\beta$ orthogonal 
coordinates $\left(v_{S \alpha}\right.$ and $\left.v_{S \beta}\right)$. Similarly, the three-phase load currents are transformed into two-phase $\alpha-\beta$ orthogonal coordinates ( $i_{L \alpha}$ and $\left.i_{L \beta}\right)$ in (22).

$$
\begin{aligned}
& \left(\begin{array}{l}
v_{S \alpha} \\
v_{S \beta}
\end{array}\right)=\sqrt{\frac{2}{3}}\left(\begin{array}{ccc}
1 & -\frac{1}{2} & -\frac{1}{2} \\
0 & \frac{\sqrt{3}}{2} & -\frac{\sqrt{3}}{2}
\end{array}\right)\left(\begin{array}{l}
v_{S a} \\
v_{S b} \\
v_{S c}
\end{array}\right) \\
& \left(\begin{array}{l}
i_{L \alpha} \\
i_{L \beta}
\end{array}\right)=\sqrt{\frac{2}{3}}\left(\begin{array}{ccc}
1 & -\frac{1}{2} & -\frac{1}{2} \\
0 & \frac{\sqrt{3}}{2} & -\frac{\sqrt{3}}{2}
\end{array}\right)\left(\begin{array}{l}
i_{L a} \\
i_{L b} \\
i_{L c}
\end{array}\right)
\end{aligned}
$$

From (21) and (22), the instantaneous real power $\left(p_{L}\right)$ and the instantaneous imaginary power $\left(q_{L}\right)$ flowing into the load side are computed in (23) [10].

$$
\left(\begin{array}{c}
p_{L} \\
q_{L}
\end{array}\right)=\left(\begin{array}{cc}
v_{S \alpha} & v_{S \beta} \\
v_{S \beta} & -v_{S \alpha}
\end{array}\right)\left(\begin{array}{l}
i_{L \alpha} \\
i_{L \beta}
\end{array}\right)
$$

Let $\bar{p}_{L}$ and $\tilde{p}_{L}$ are the average component and the oscillating component of $p_{L}$, respectively, and $\bar{q}_{L}$ and $\tilde{q}_{L}$ are the average component and the oscillating component of $q_{L}$, respectively. Therefore, these may be expressed as

$$
\begin{aligned}
& p_{L}=\bar{p}_{L}+\tilde{p}_{L}, \\
& q_{L}=\bar{q}_{L}+\tilde{q}_{L} .
\end{aligned}
$$

In (24), the fundamental component of the load current is transformed to average components $\bar{p}_{L}$ and $\bar{q}_{L}$, and the harmonics are transformed to oscillating components $\tilde{p}_{L}$ and $\tilde{q}_{L}$. The average components can be separated by using lowpass filters or using a Moving Average Filter (MAF). The use of MAF ensures a faster dynamic response to the load steps and a better compensation of low order current harmonics [7].

The VSC reference currents into two-phase $\alpha-\beta$ orthogonal coordinates $i_{F \alpha}^{*}$ and $i_{F \beta}^{*}$ are obtained as

$$
\left(\begin{array}{l}
i_{F \alpha}^{*} \\
i_{F \beta}^{*}
\end{array}\right)=\frac{1}{v_{S \alpha}{ }^{2}+v_{S \beta}{ }^{2}}\left(\begin{array}{cc}
v_{S \alpha} & v_{S \beta} \\
v_{S \beta} & -v_{S \alpha}
\end{array}\right)\left(\begin{array}{l}
p^{*} \\
q^{*}
\end{array}\right),
$$

where $p^{*}$ and $q^{*}$ are the reference real and imaginary powers that the SAF must compensate. Since $P_{\text {LOSS }}$ is the active instantaneous power required to regulate the DC bus voltage and $P_{P V}$ is the PV Array power generated, the reference powers are expressed as

$$
\begin{gathered}
p^{*}=P_{\text {LOSS }}-P_{P V}-\tilde{p}_{L}, \\
q^{*}=-q_{L} .
\end{gathered}
$$

To perform the vector control of the VSC currents, $i_{F \alpha}^{*}$ and $i_{F \beta}^{*}$ are transformed into d-q coordinates by using the Park's Transformation in (27). The $d-q$ axes are in synchronism with

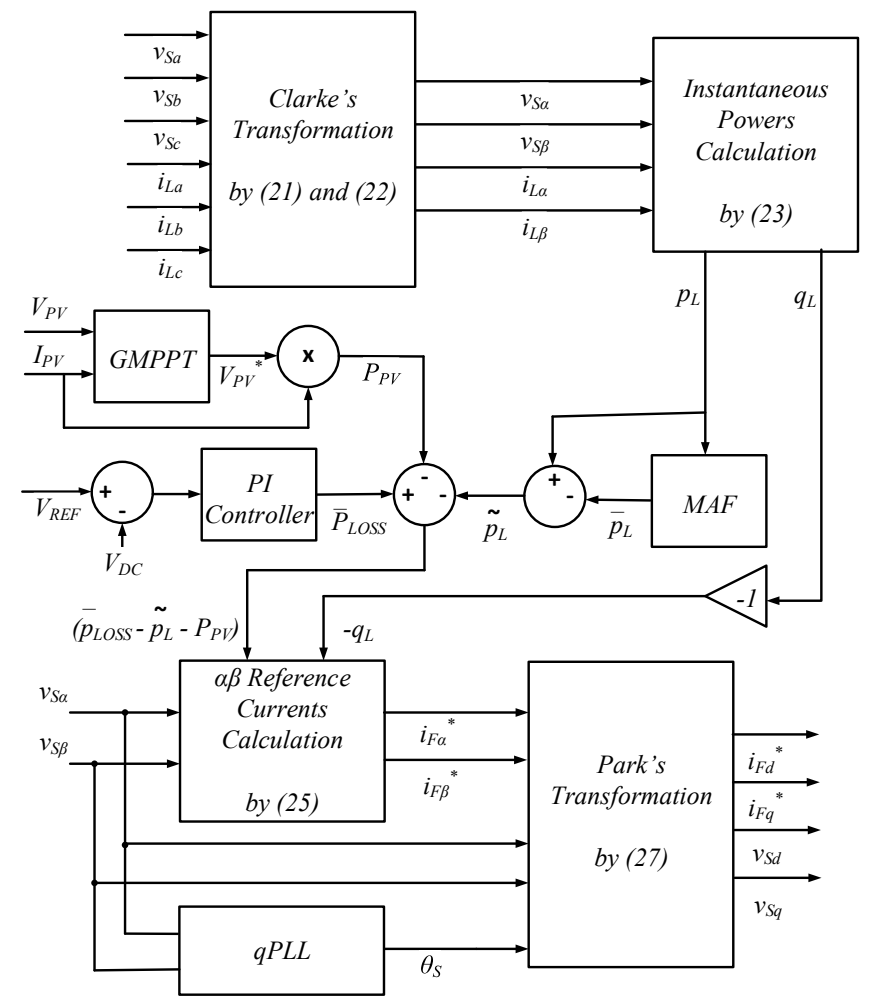

Fig. 3. Shunt active power filter using $P Q$ theory scheme control.

the supply voltage, the supply voltage phase angle $\left(\theta_{S}\right)$ is obtained by using the quadrature Phase Locked-Loop (qPLL).

$$
\left(\begin{array}{l}
i_{F d}^{*} \\
i_{F q}^{*}
\end{array}\right)=\left(\begin{array}{cc}
\sin \left(\theta_{S}\right) & -\cos \left(\theta_{S}\right) \\
\cos \left(\theta_{S}\right) & \sin \left(\theta_{S}\right)
\end{array}\right)\left(\begin{array}{l}
i_{F \alpha}^{*} \\
i_{F \beta}^{*}
\end{array}\right)
$$

Fig. 4 shows the vector control scheme of the VSC currents. There is a control loop for $i^{*} F d$ and another for $i_{F q}^{*}$, the controllers outputs are the reference voltages of the VSC into d-q coordinates $\left(\mathrm{v}_{F d}^{*} \mathrm{e} \mathrm{v}_{F q}^{*}\right)$ [19]. The reference voltages $\mathrm{v}^{*}{ }_{F d}$ and $\mathrm{v}^{*}{ }_{F q}$ are transformed into abc coordinates by using the Inverse Clark and Park Transformation in (28).

$$
\begin{aligned}
& \left(\begin{array}{l}
v_{F a}^{*} \\
v_{F b}^{*} \\
v_{F c}^{*}
\end{array}\right)
\end{aligned}
$$

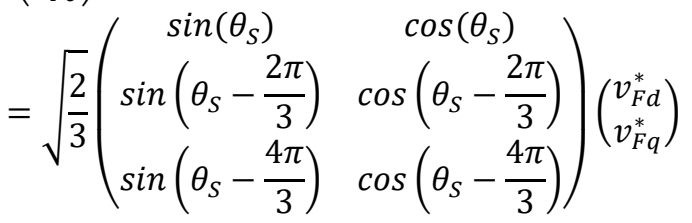

Fig. 4. Reference currents vectorial control scheme. 
The Space Vector modulation is used to generate the VSC switching commands [20].

\section{Test Results Validation}

To validate the proposed PV-SAF system strategies control, the system was simulated in PSIM software.

Fig. 5 shows the p-v curves of PV array in both operating conditions simulated. Starting in Case 1, in this situation, all the $30 \mathrm{PV}$ array modules are irradiated at $1000 \mathrm{~W} / \mathrm{m}^{2}$ and the temperature is $50^{\circ} \mathrm{C}$. At time $t=265 \mathrm{~ms}$, the PV Array operating condition is changed to Case 2 . In this case, 5 modules are shaded and their irradiances change to $200 \mathrm{~W} / \mathrm{m}^{2}$, the remaining 25 modules continue with $1000 \mathrm{~W} / \mathrm{m}^{2}$. The modules temperature continues at $50^{\circ} \mathrm{C}$ in Case 2 .

Fig. 6 presents the PV-SAF system dynamic performance when occurs changes in irradiance on the PV array modules. In $t=130 \mathrm{~ms}$ the GMPPT algorithm is started. After irradiance decreasing in some PV Array modules (from Case 1 to Case 2), the generated power decreases and the GMPPT algorithm detects this change, tracks again and reaches a new operating point where the DC bus voltage is lower. It can be observed that the generated power decrease $64.5 \%$ after 5 modules are shaded while the DC bus voltage is maintained the same. However, after the correct GMPPT algorithm proceeding and the new GMPP reach, the generated power decrease only $14.3 \%$ after the 5 modules shaded. From the tracking start to the steady-state, the average GMPPT search time is $58 \mathrm{~ms}$.

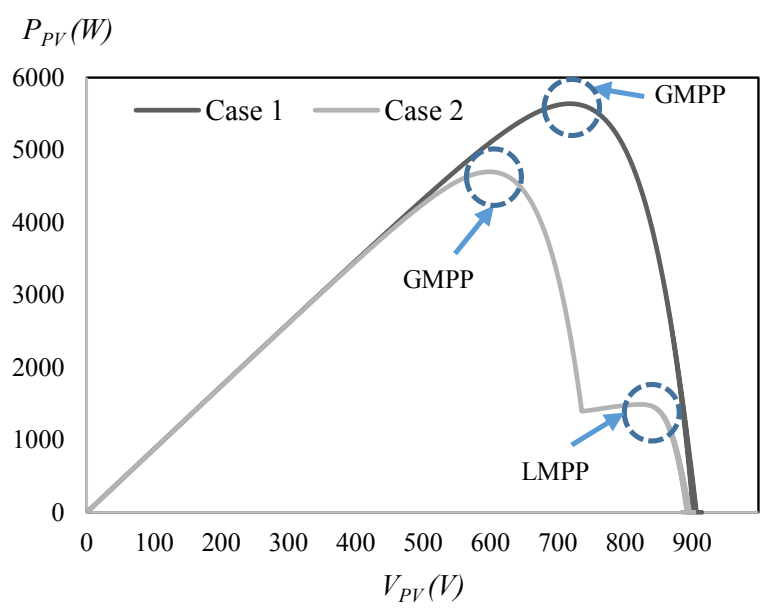

Fig. 5. P-v curves of Case 1 and Case 2 situations.

Fig. 7 shows the PV-SAF system performance in steadystate during Case 1 conditions. The DC bus voltage is $730 \mathrm{~V}$, which is the PV array maximum power voltage in Case 1 conditions and was set by the GMPPT algorithm. It can be observed that the supply current is sinusoidal and has acceptable switching frequency ripple, since the system is operating with a DC bus voltage lower than the maximum designed DC bus voltage (774V). While the load current THD (total harmonic distortion) is $25.76 \%$, the source current THD is reduced to $3.39 \%$ due the active filtering performance. The power factor (PF) seen on the load side is 0.79 while the seen
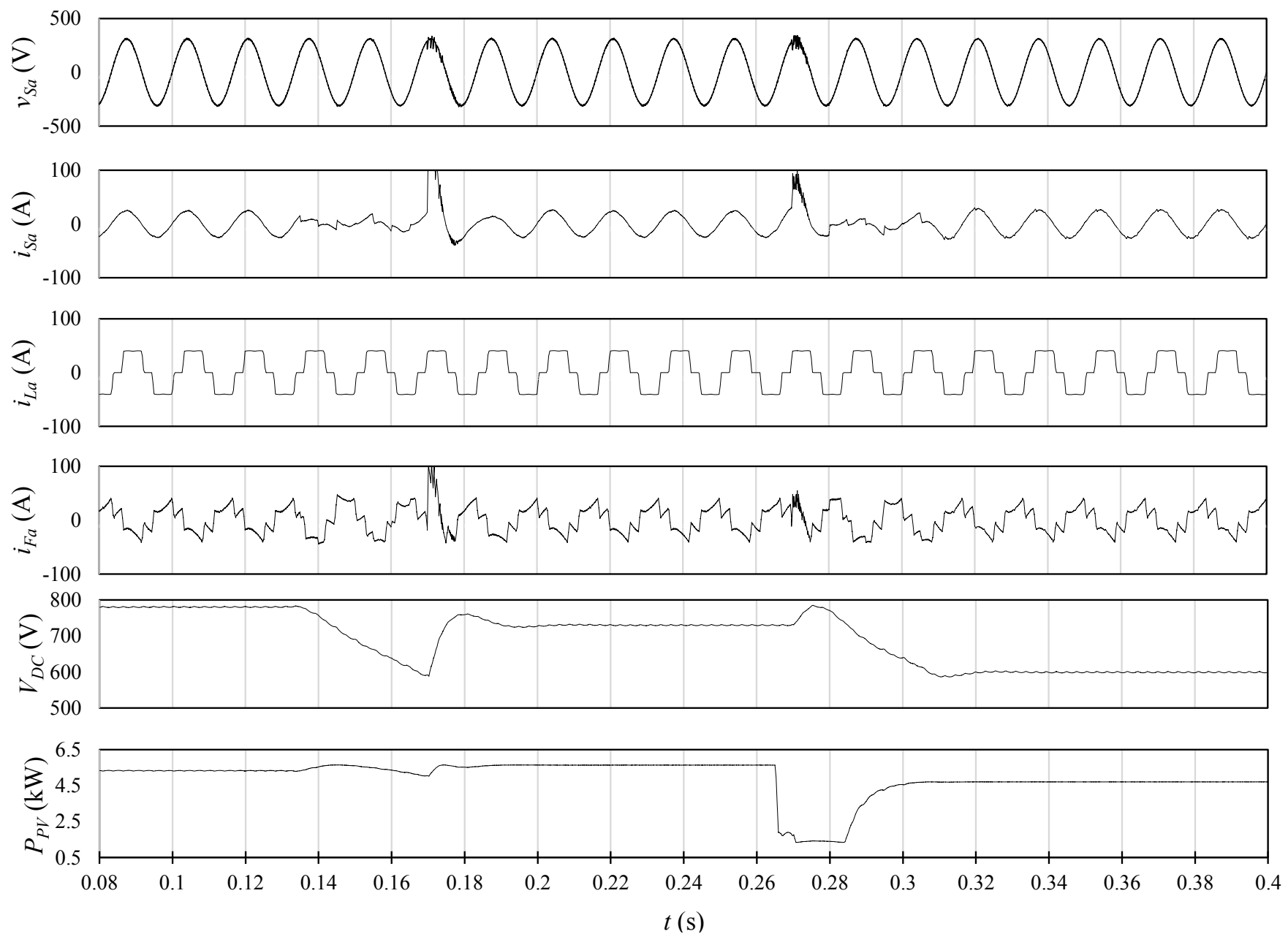

Fig. 6. Performance of $P V-S A F$ under change in irradiance. 

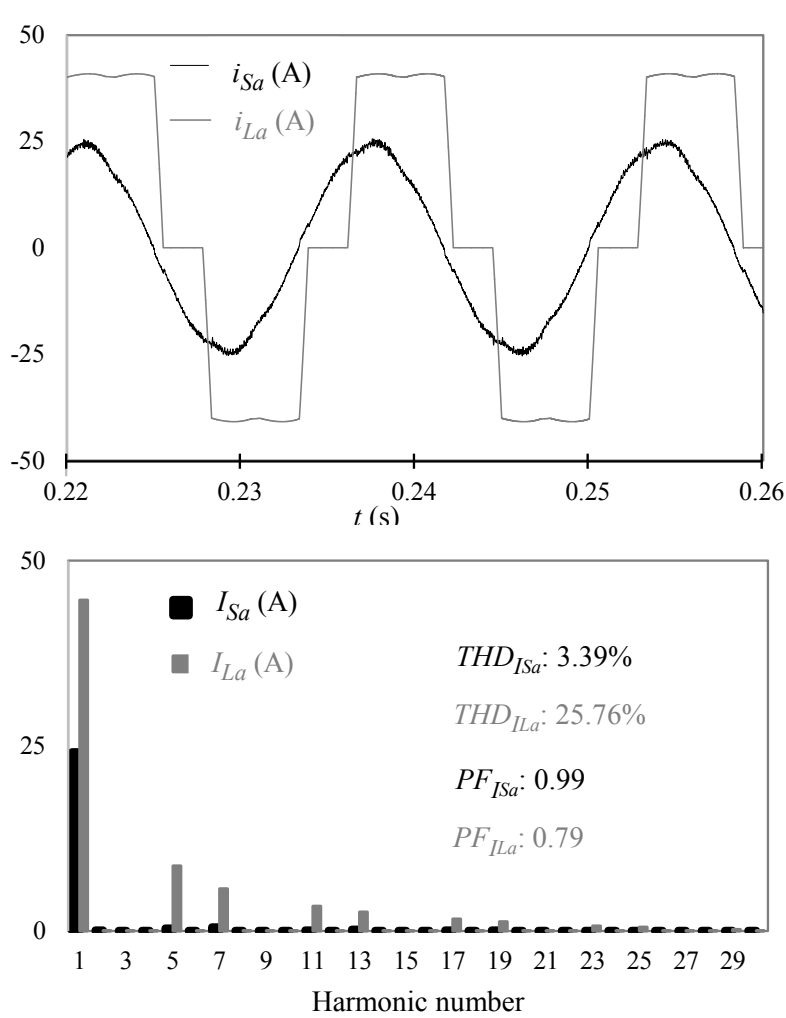

Fig. 7. Supply and load currents in Case 1 (USC) steady-state situation.

on the source side is improved to 0.99 . In this situation, the $\mathrm{PV}$ array generated power is $5.63 \mathrm{~kW}$, i.e., the PV-SAF system is compensating $100 \%$ of the reactive and harmonic load powers and still compensates $31.5 \%$ of the load active power.

Fig. 8 presents the PV-SAF system performance in steadystate during Case 2 conditions. It can be observed that the supply current has more low order harmonics and less harmonics near the switching frequency than when the system is in Case 1 conditions. Due to the shaded modules, the MPP voltage is lower $(598 \mathrm{~V})$ and this decrease the system ability to compensate the abrupt change in load current. However, as the system is designed to operate with a minimum voltage of $590 \mathrm{~V}$ on the DC bus, harmonic compensation is still satisfactorily performed and the source current THD is reduced to $4.26 \%$. In this situation, the PV array generated power is $4.70 \mathrm{~kW}$, i.e., the PV-SAF system is compensating $100 \%$ of the reactive and harmonic load powers and still compensates $26.3 \%$ of the load active power.

The supply currents THD in steady-state is within the IEEE-519 standard limits in both irradiance conditions analyzed.

When the PV array generated power is approximately equal to the load active power, the supply current will be very low and its THD index may exceed $5 \%$.

\section{CONCLUSION}

In this paper, a PV-SAF single-stage system using PQ theory and a new GMPPT technique has been presented for a three-phase and three-wire grid and non-linear load integrated. The validation of the model and control has been carried out through simulations done in PSIM. The main advantage of the proposed system is the possibility of use and execute a GMPPT algorithm even when using the single-stage topology for PV-SAF system. The simulations results have shown that
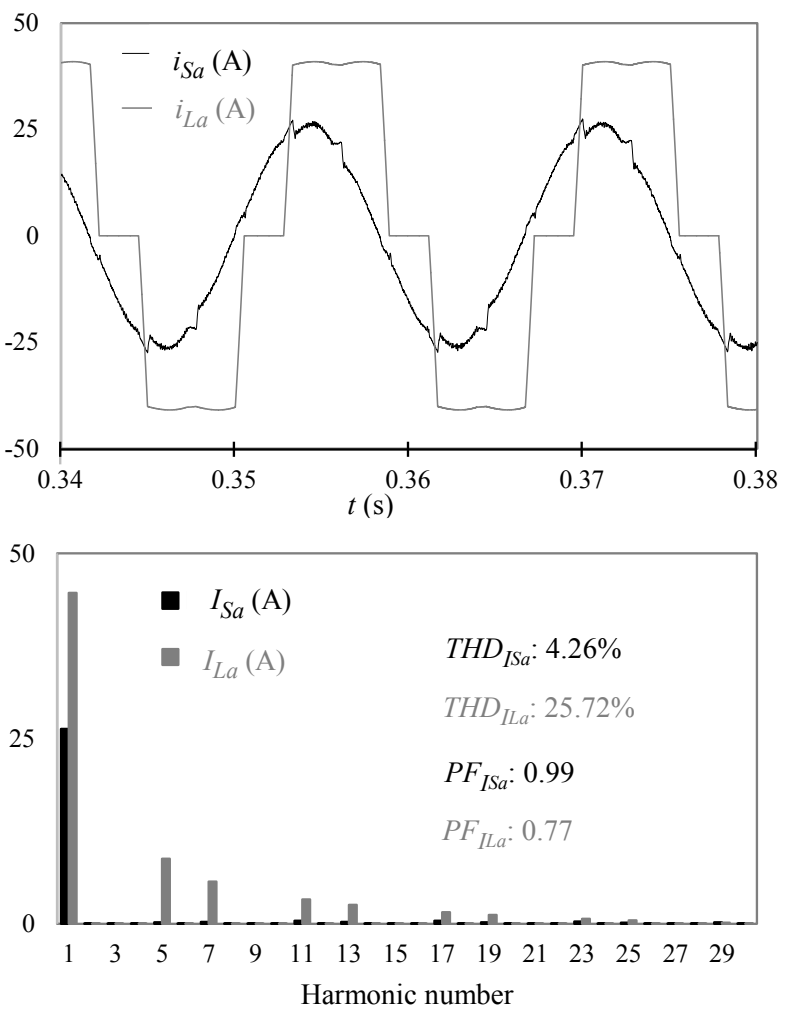

Fig. 8. Supply and load currents in Case 2 (PSC) steady-state situation.

the proposed PV-SAF system has performed satisfactorily under non-linear loads and variable solar irradiance. The GMPPT algorithm is competent to detect changing in irradiance condition and to track the PV array maximum power point even in partial shading condition. Apart from injecting the maximum possible power extracted from the PV array into the grid, the proposed PV system also provides reactive power compensation as well as harmonic elimination in day time and also during night. The harmonic compensation was satisfactory across the designed DC bus voltage range. The level of harmonics injected in the grid currents in considered conditions is within limits and recommendations to the IEEE-519 standard.

\section{ACKNOWLEDGMENT}

P.R.M.C. is thankful to CAPES (Coordenação de Aperfeiçoamento de Pessoal de Nível Superior).

\section{REFERENCES}

[1] REN21, "Renewables 2018 global status report," ISBN 978-39818911-3-3, 2018.

[2] H. Vahedi, P. Labbe, and K. Al-Haddad, "Sensor-less five-level packed U-cell inverter operating in stand-alone and grid-connected modes," IEEE Trans. Ind. Informat., vol. 12, no. 1, pp. 361-370, Feb. 2016.

[3] E. I. Batzelis, P. S. Georgilakis, S. A. Papathanassiou, "Energy models for photovoltaic systems under partial shading conditions: a comprehensive review", IET Renew. Power Gener., vol. 9, Iss. 4, pp. 340-349, 2015.

[4] I. R. Balasubramanian, S. I. Ganesan, N. Chilakapati, "Impact of partial shading on the output power of PV systems under partial shading conditions", IET Power Eletron., vol. 7, Iss. 3, pp. 657-666, 2014.

[5] T. Esram and P. L. Chapman, "Comparison of photovoltaic array maximum power point tracking techniques," IEEE Trans. Energy Conversion, vol. 22, no. 2, pp. 439-449, Jun. 2007.

[6] S. Kumar, I. Hussain, B. Singh, A. Chandra and K. Al-Haddad, "An Adaptive Control Scheme of SPV System Integrated to AC 
Distribution System," IEEE Trans. Ind. Appl., vol. 53, no. 6, pp. 51735181, Nov./Dec. 2017.

[7] S. Devassy and B. Singh, "Design and Performance Analysis of ThreePhase Solar PV Integrated UPQC," IEEE Trans. Ind. Appl., vol. 54, no. 1, pp. 73-81, Jan./Feb. 2018.

[8] R. K. Agarwal, I. Hussain and B. Singh, "Three-phase single-stage grid tied solar PV ECS using PLL-less fast CTF control technique", IET Power Eletron., vol. 10, Iss. 2, pp. 178-188, 2016.

[9] B. Singh, A. Chandra, and K. Al-Haddad, Power Quality: Problems and Mitigation Techniques. New Delhi, India: Wiley-Blackwell, Jan. 2015.

[10] H. Akagi, E. H. Watanabe and M. Aredes, Instantaneous power theory and applications power conditioning. New Jersey: Wiley-IEEE Press, 2007.

[11] B. Yahia, D. Hind and C. Rashid, "The Application of an Active Power Filter on a Photovoltaic Power Generation System", Inter. Journal of Renew. Energy Res., vol. 2, no. 4, pp. 583-590, 2012.

[12] N. Shah, C. Rajagopalan, "Experimental investigation of a multifunctional grid interactive photovoltaic system operating in partial shading conditions", IET Renew. Power Gener., vol. 10, Iss. 9 , pp. 1382-1392, 2016.

[13] S. Kumar and B. Singh, "A Multipurpose PV System Integrated to a Three-Phase Distribution System Using an LWDF-Based Approach," IEEE Trans. Power Eletron., vol. 33, no. 1, pp. 739-748, Jan. 2018.
[14] IEEE 519 Recommended Practices and Requirements for Harmonic Control in Electrical Power Systems, IEEE Standard, 2014.

[15] K. V. Kumar, P. A. Michael, J. P. John and S. S. Kumar, "Simulation and comparison of SPWM and SVPWM control for three phase inverter", ARPN Journal of Engineering and Applied Sciences, vol. 5, no. 7, Jul. 2010.

[16] I. M. Syed, K. Raahemifar, "Space Vector PWM and Model Predictive Control for Voltage Source Inverter Control", International Journal of Industrial and Manufacturing Engineering, vol. 8, no. 11, 2014.

[17] R. L. de A Ribeiro, C. C. de Azevedo and R. M. de Sousa, "A Robust Adaptive Control Strategy of Active Power Filters for Power-Factor Correction, Harmonic Compensation, and Balancing of Nonlinear Loads", IEEE Trans. Power Eletron., vol. 27, no. 2, pp. 718-730, Feb. 2012.

[18] J. Ahmed and Z. Salam, "An Improved Method to Predict the Position of Maximum Power Point During Partial Shading for PV Arrays," IEEE Trans. Ind. Informat., vol. 11, no. 6, pp. 1378-1387, Dec. 2015.

[19] R. Pena, J. C. Clare and G. M. Asher, "Doubly fed induction generator uising back-to-back PWM converters and its application to variable speed wind-energy generation", IEE Proc. Electr. Power Appl., vol. 143, no. 3, May. 1996.

[20] V. V. Bhandankar and A. J. Naik, "Simulation of Space Vector Modulation in PSIM", International Journal of Engineering and Sciences, vol. 8, iss. 2, pp. 49-53, 2016. 